\title{
EROSIVIDADE DA CHUVA NA REGIÃO DO MÉDIO SOLIMÕES, AMAZONAS, BRASIL
}

\author{
João Cândido André da Silva Neto \\ Universidade Federal do Amazonas, Manaus, AM, Brasil \\ joaocandido@ufam.edu.br \\ Natacha Cíntia Regina Aleixo \\ Universidade Federal do Amazonas, Manaus, AM, Brasil \\ natachaaleixo@ufam.edu.br
}

\begin{abstract}
RESUMO
O objetivo do presente trabalho foi analisar a erosividade da chuva na região do Médio Solimões no estado do Amazonas, Brasil, a partir uma série histórica de dados de 1992 a 2012, retirados de trinta e duas (32) estações meteorológicas distribuídas na região. O valor médio do índice de erosividade foi determinado conforme a proposta de Lombardi Neto e Moldenhauer (1992), implementado no software de geoprocessamento Quantum GIS (QGIS) 2.18. Os índices de erosividade mensal na região apresentaram uma sazonalidade em que predomina índices de erosividade superiores a $700 \mathrm{MJ} \mathrm{mm} \mathrm{ha-1} \mathrm{h}-^{-1}$ mês-1, o que corresponde às classes Muito Alta e Alta, os índices foram observados entre os meses de dezembro e maio. Do mês de junho até o mês de setembro, observou-se a diminuição dos índices mensais de erosividade, predominando valores inferiores a $500 \mathrm{MJ} \mathrm{mm} \mathrm{ha-}^{-1} \mathrm{~h}^{-1} \mathrm{mês}^{-1}$. Nos meses de outubro e novembro, os índices de erosividade voltam a aumentar, caracterizandose como uma transição entre período seco e chuvoso na região do Médio Solimões. Os índices de erosividade anual predominantes na região foram valores superiores a $7000 \mathrm{MJ}$ $\mathrm{mm}$ ha- $^{-1} \mathrm{~h}^{-1}$ ano-1, correspondendo às classes Muito Alta e Alta.
\end{abstract}

Palavras-chave: Erosão. Precipitação pluviométrica. Amazônia.

\section{RAINFALL EROSIVITY IN REGION OF MIDDLE SOLIMÕES, AMAZONAS STATE, BRAZIL}

\begin{abstract}
The goal of this survey was to was to analyze the rainfall erosivity in region of Médio Solimões, Amazonas state, Brazil, from a historical data series from 1992 to 2012, using data from thirtytwo (32) meteorological stations distributed in the region. The determination of the mean value of the erosivity index was as proposed by Lombardi Neto and Moldenhauer (1992), implemented in Quantum GIS geoprocessing software (QGIS) 2.18. Monthly erosivity indexes in the region present a seasonality in which erosivity indexes higher than $700 \mathrm{MJ} \mathrm{mm} \mathrm{ha-1} \mathrm{h}$ 1 month-1 correspond to the Very High and High classes, observed between the months of December and May. From June to September, the monthly erosivity indexes decrease, with

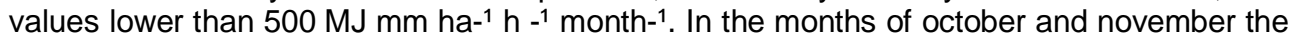
rates of erosivity increase again, characterizing as a transition between dry and rainy season in the region of Middle Solimões. The annual erosivity indexes prevailing in the region were values higher than $7000 \mathrm{MJ} \mathrm{mm} \mathrm{ha-1} \mathrm{h}^{-1}$ year-1, corresponding to the Very High and High classes.
\end{abstract}

Keywords: Erosion. Rainfall. Amazon.

\section{INTRODUÇÃO}

Erosão pode ser entendida como um processo complexo influenciado por vários fatores, de forma e magnitude variável, de acordo com as características de cada localidade onde o processo se manifesta (SILVA, et al. 2007).

Silva, et al. (2007), consideraram ainda que os processos erosivos estão diretamente associados aos cinco fatores principais, são eles: tipos de solos, embasamento geológico, clima, relevo, uso da terra, coberturas vegetais e tipos de manejos. 
Para Wischmeier e Smith (1978), a relação dos fatores que influenciam os processos erosivos em um local é determinada pela maneira particular em que as diferentes variáveis físicas relacionam-se e são combinadas em um determinado local.

Os processos erosivos, são processos naturais que podem ser intensificados pelas intervenções humanas na natureza. Essas alterações nas dinâmicas da natureza, quando não respeitados seus limites físicos-naturais, tendem a gerar impactos diretos que influenciam e são influenciados pelo uso e ocupação da terra, devido à perda de terras produtivas ocasionadas por esses processos.

Para Pruski (2006), a erosão origina-se no rompimento do equilíbrio natural no solo, em decorrência da ação de forças advindas de fatores climáticos como chuva e vento, que se associado a outros fatores, acabam por determinar a intensidade do processo erosivo, como os diferentes tipos e intensidades de usos da terra.

Assim, a erosão pode ser entendida como um problema de ordem socioambiental, por extrapolar os limites físicos-naturais das paisagens, influenciando diretamente nas dinâmicas natureza e sociedade.

Wischmeier e Smith (1978), no guia "Predicting rainfall erosion losses - a guide to conservation planning", estabeleceu uma equação a USLE (Universal Soil Loss Equation) que visava integrar os fatores determinantes para o desencadeamento dos processos erosivos, como a erodibilidade dos solos (fator K), relevo (fator topográfico LS), cobertura vegetal, manejo e práticas conservacionistas (CV) bem como a erosividade da chuva (fator R), a fim de se estabelecer estimativas de perda de solos, medidas conservacionistas e planos de manejos.

O fator erosividade da chuva $(\mathrm{R})$ é definido como o índice de erosão da chuva de um local, que visa uma avaliação numérica do valor médio anual da chuva de um local, expressando a capacidade daquela chuva de erodir o solo de um terreno desprotegido de vegetação (LOMBARDI NETO e MOLDENHAUER,1992).

O valor numérico utilizado para o fator erosividade $(R)$ na equação de perda de solo deve quantificar o efeito de impacto da chuva e também deve fornecer informações relativas à quantidade e a taxa de escoamento provavelmente associados à chuva. (WISCHMEIER e SMITH, 1978).

Silva (2004), definiu a erosividade das chuvas como a potencial capacidade de chuva para causar perda de solo.

Nesse sentido, o objetivo do presente artigo foi analisar a erosividade das chuvas na região do Médio Solimões no estado do Amazonas, Brasil. Considerando uma série histórica de dados de 1992 a 2012, em que foram utilizados os dados de trinta e duas (32) estações meteorológicas distribuídas na região.

Enfatiza-se que os outros fatores da USLE (Universal Soil Loss Equation), não foram abordados nesse momento, porque o foco do trabalho foi estabelecer uma caracterização da erosividade das chuvas na região abordada.

O presente estudo justifica-se pelo entendimento da erosividade como o potencial das chuvas em desencadear os processos erosivos, considerado como um fator primordial para se analisar e estimar perda de solos, podendo ainda auxiliar as diretrizes para implementação de medidas de manejo na região do Médio Solimões na Amazônia brasileira.

Guerra (2005), considerou que os processos de desgastes dos solos desencadeados pela precipitação pluviométrica compreendem quase toda superfície terrestre, recebendo destaque as áreas localizadas na zona intertropical, onde os totais pluviométricos são bem mais elevados do que em outras regiões do planeta, observando, em contrapartida, que em áreas onde há concentração de chuvas durante algumas estações do ano, os processos erosivos são mais intensos.

Silva (2004), corroborando com Guerra (2005), afirma que a região Amazônica se caracteriza por apresentar os maiores índices de erosividade no Brasil.

Outro ponto que deve ser considerado, segundo Trindade et al. (2016), é que a Bacia Amazônica apresenta a maior área territorial, no contexto nacional, porém, apresenta a menor série histórica de dados e de densidade de estações meteorológicas, em relação à área, o que contribui para ausência de estudos nessa temática na região.

Assim, o presente estudo justifica-se ainda pela ausência de pesquisas desse tipo para região do Médio Solimões, que poderiam auxiliar nos planos de manejo para conservação dos solos na região. 


\section{METODOLOGIA}

\section{Área de estudo}

A área abordada para estudo compreende os municípios de Coari, Tefé, Alvarães, Uarini, Carauari e Juruá, localizados na Região do Médio Solimões no estado do Amazonas, Brasil. Segundo Ross (2006) a região do Médio Solimões é caracterizada como sistemas ambientais naturais pouco transformados, apresenta características marcantes do ponto de vista de sua compartimentação geomorfológica definida como bacias e coberturas sedimentares Fanerozóicas e Depósitos Sedimentares Quaternários, em que predominam baixas altitudes que oscilam entre 20 metros e no máximo 140 metros aproximadamente (IBGE, 2018).

Segundo Maia e Marmos (2010), quanto às unidades litológicas da área, verifica-se formações recentes do Cenozóico, Terraços Fluviais do pleistoceno, sedimento fluvial arenoso, siltoso e cascalheira, geralmente inconsolidados.

Os terraços fluviais correspondem a amplos depósitos sedimentares constituídos por argila, areia e cascalho, via-de-regra, inconsolidados a semi-consolidados e com dezenas de metros de espessura.

Figura 1 - Mapa de localização da área de estudo.

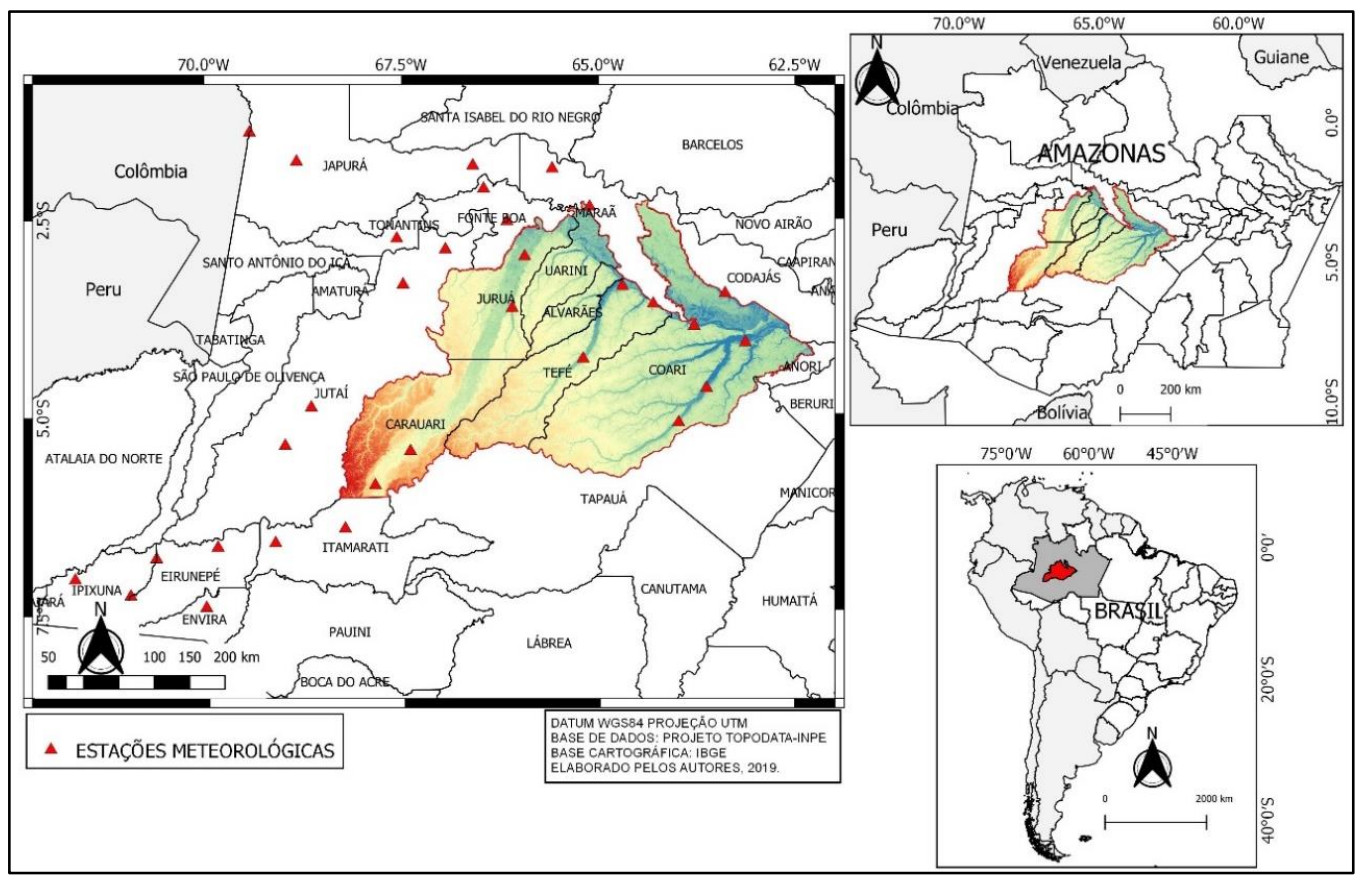

Fonte - IBGE, 2018; TOPODATA-INPE, 2011. Org: Autores, 2019.

Os depósitos aluvionares do holoceno caracterizam-se pelos sedimentos de canal fluvial e da planície de inundação, arenoso, siltoso e argiloso, com níveis de cascalho. Depósito lacustre argiloso, arenoso fino com matéria orgânica, revela uma morfologia característica de planície sedimentar onde é comum o padrão de canais fluviais meandrantes, lagos de variada conformação e meandros abandonados que registram a migração lateral do curso dos rios. A planície encontra-se representada por sedimentos arenosos a argilosos inconsolidados a semiconsolidados, associando-lhes níveis de cascalho e matéria orgânica (MAIA e MARMOS, 2010).

A Formação Içá é caracterizada por arenitos ferruginosos, siltitos, argilitos e subordinadas lentes turfáceas. Reúne ainda arenitos amarelo-avermelhados, finos a conglomeráticos, friáveis, com siltitos subordinados e argilitos de características eminentemente continentais e depositados sob condições fluviais de elevada energia e clima árido (IBGE, 2018; MAIA e MARMOS, 2010). Os solos predominantes na região são os Argissolos Vermelho-amarelo, Gleissolos, Plintossolos, Neossolos Quartzarênicos, verificando-se ainda pequenas áreas de Latossolos e Espodossolos (IBGE, 2018; EMBRAPA, 2006). 


\section{Procedimentos metodológicos}

Foram consultados trabalhos que abordassem a Erosividade na região Amazônica, região Norte do Brasil e Erosividade em um contexto geral, assim, foram selecionados os trabalhos que contemplavam a temática da pesquisa, como de Silva (2004), intitulado "Rainfall erosivity map for Brazil"; e Costa et al. (2013), que abordou o potencial erosivo e índice de anomalias de chuvas no polo de produção de grãos de Paragominas, Pará. A consulta abrangeu os trabalhos de Lima et al. (2014), que faz uma análise do fator de erosividade da chuva para uma pequena bacia hidrográfica da Amazônia; Trindade et al. (2016), que abordaram a variabilidade espacial da erosividade das chuvas no Brasil; Souza e Galvani (2014), que analisaram a determinação do índice de erosividade das chuvas para o município de Umuarama - PR; e Pereira e Rodrigues (2018), que analisou a erosividade das chuvas na área de influência da UHE Aguiar I, na bacia do rio Araguari - MG.

Foram consultados ainda trabalhos relevantes sobre equação universal de perda de solos e índice de erosividade, a saber: Lombardi Neto e Moldenhauer, (1992), Wischmeier e Smith (1978), Bertoni e Lombardi Neto (1999).

Foram coletados dados de precipitação pluvial (mensais e anuais), na Agência Nacional de Águas (ANA) pela plataforma Hidroweb. Em decorrência da qualidade e disponibilidade dos dados, foi escolhido o período de 1992 a 2012 para análise. Também foram utilizados dados das estações do Instituto Nacional de Meteorologia (INMET) na região.

Para as estações que apresentaram dados mensais faltantes, foram utilizados dados das estações mais próximas e aplicadas técnicas de preenchimento de falhas, como a regressão linear e, no caso da estação se situar em área distante de outro posto meteorológico, utilizou-se também da média estatística dos dados da própria estação pelo maior período de tempo disponível.

Verificou-se que, na região do Médio Solimões, a presença de estações meteorológicas é escassa, ou seja, boa parte apresentou falhas nos dados, sendo necessário utilizar-se de estações fora do limite da região para realização da interpolação dos dados em perspectiva regional. Foram selecionadas 32 estações meteorológicas para compor a análise regional da precipitação pluvial na região, conforme a Figura 1.

A determinação do valor médio do índice de erosividade por meio da relação entre a média mensal e a média anual de precipitação foi realizada conforme a equação (1) proposta por Lombardi Neto e Moldenhauer (1992):

$E I=67,355 *\left(\frac{r^{2}}{P}\right)^{0,85}$

Onde:

$E l=$ média mensal do índice de erosividade, em MJ/ha.mm;

$r=$ média mensal de precipitação, em $\mathrm{mm}$;

$P=$ média anual de precipitação, em $\mathrm{mm}$

Para a determinação de erosividade anual $(\mathrm{R})$ somou-se os valores mensais do índice de erosividade para toda a série histórica (2).

$\mathrm{R}=\sum E I$

Onde:

$\mathrm{R}=$ erosividade da chuva (MJ/ha.mm/ano)

$\mathrm{El}=$ média mensal do índice de erosividade

Após o tratamento estatístico dos dados de precipitação e erosividade, realizou-se a interpolação dos dados utilizando-se o método Ponderação do Inverso das Distâncias (Inverse Distance Weighting), o qual estima medidas desconhecidas de um campo contínuo para locais onde não há medidas disponíveis (LONGLEY, et al. 2013).

Para Camargo et al. (2004) a formulação geral para este tipo de interpolação obedece a equação (3):

$$
\hat{Z} i=\frac{\sum_{j=1}^{n} W i j Z j}{\sum_{j=1}^{n} W i j}
$$


Onde:

$Z i$ é o valor de cota de um ponto $i$ qualquer da grade; $Z j$ é a cota de uma amostra $j$ vizinha do ponto $i$ da grade e Wij é um fator de ponderação.

A implementação do tratamento geoestatístico foi realizado no software gratuito de geoprocessamento Quantum GIS (QGIS) 2.18.

\section{RESULTADOS E DISCUSSÃO}

No período de 1992 a 2012, verificou-se que as médias mensais de chuvas apontam para a sazonalidade distinta na região. O período mais chuvoso concentrou-se entre os meses de dezembro e maio. Em junho, ocorre a diminuição das médias mensais de precipitação pluvial abaixo de $200 \mathrm{~mm}$. Neste cenário, o mês de agosto apresenta a menor média; $116 \mathrm{~mm}$. Dessa maneira, os meses de junho a outubro são considerados representativos do período mais seco. A partir de outubro, o total de chuvas aumenta, porém, apenas durante o mês de novembro, com valor médio mensal superior a $200 \mathrm{~mm}$, sendo este considerado um mês transicional.

Na região, consideram-se os meses de dezembro a maio como representativos do período chuvoso e de junho a outubro como representativos do período seco, como mostra a Figura 2.

Figura 2 - Chuvas médias mensais na região do Médio Solimões (1992-2012).

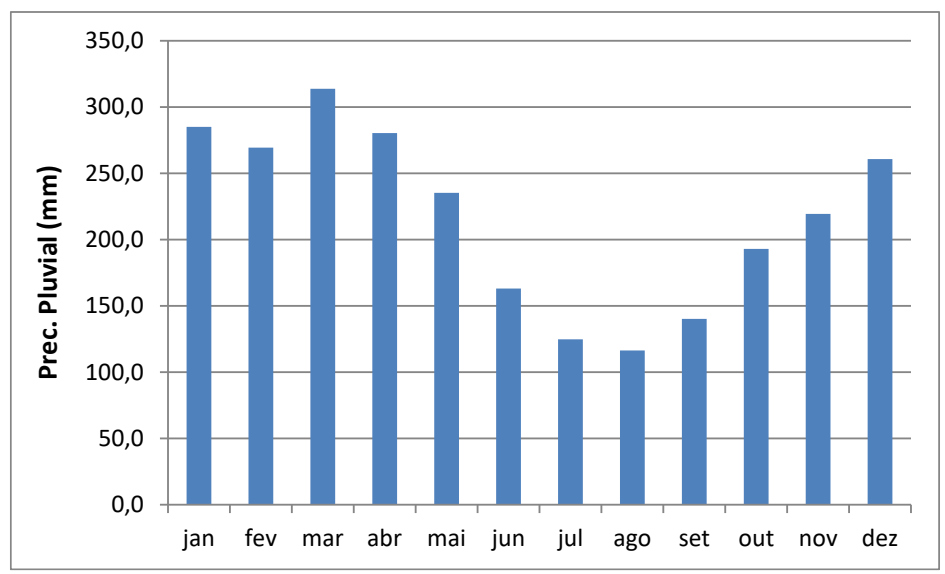

Fonte - ANA e INMET. Org.: Autores, 2019.

Na região Amazônica a precipitação pluvial é o elemento climático que demonstra a sazonalidade, pois, por localizar-se em área equatorial a insolação é elevada e a amplitude térmica mensal baixa de 1 a $2^{\circ} \mathrm{C}$. Os totais de chuvas analisados demonstraram que o período mais chuvoso concentrou-se nos meses de dezembro a maio e contribuiu com $63 \%$ do volume total da região; os meses de junho a agosto contribuíram apenas com $16 \%$ e os meses de setembro a novembro com $21 \%$ do total.

Com relação aos mecanismos de precipitação, diferentes autores têm afirmado que os sistemas de grande escala, escala sinótica, mesoescala e local, influenciam na frequência e espacialidade da chuva na região Amazônica. Sistemas como a Zona de Convergência Intertropical (ZCIT), a circulação de Walker e Hadley, a Zona de Convergência do Atlântico Sul (ZCAS), Alta da Bolívia, Linhas de Instabilidade, Frentes e sistemas convectivos locais influenciam na gênese das chuvas e sua distribuição em períodos distintos na região Amazônica. (Molion, 1987; Fisch, et al. 1998; Marengo e Nobre, 2009).

Na região do Médio Solimões, os maiores totais anuais de precipitação pluvial ocorreram na porção norte e sudoeste, nos municípios de Uarini e Juruá em parte de Tefé e Carauari, com totais superiores a $3200 \mathrm{~mm}$ anuais nos postos pluviométricos. As isoietas anuais da região do Médio Solimões mostram que a porção norte é a que concentra os volumes anuais de chuvas elevados seguida da parte central, provocadas pela atuação dos diferentes sistemas atmosféricos, em especial a ZCIT no período chuvoso. 
Os menores totais pluviométricos da região apresentaram-se com valores inferiores a $2100 \mathrm{~mm}$ na porção leste e oeste, compreendendo parte da área do município de Carauari, de acordo com a Figura 3.

Figura 3 - Média do total de chuva anual na região do Médio Solimões.

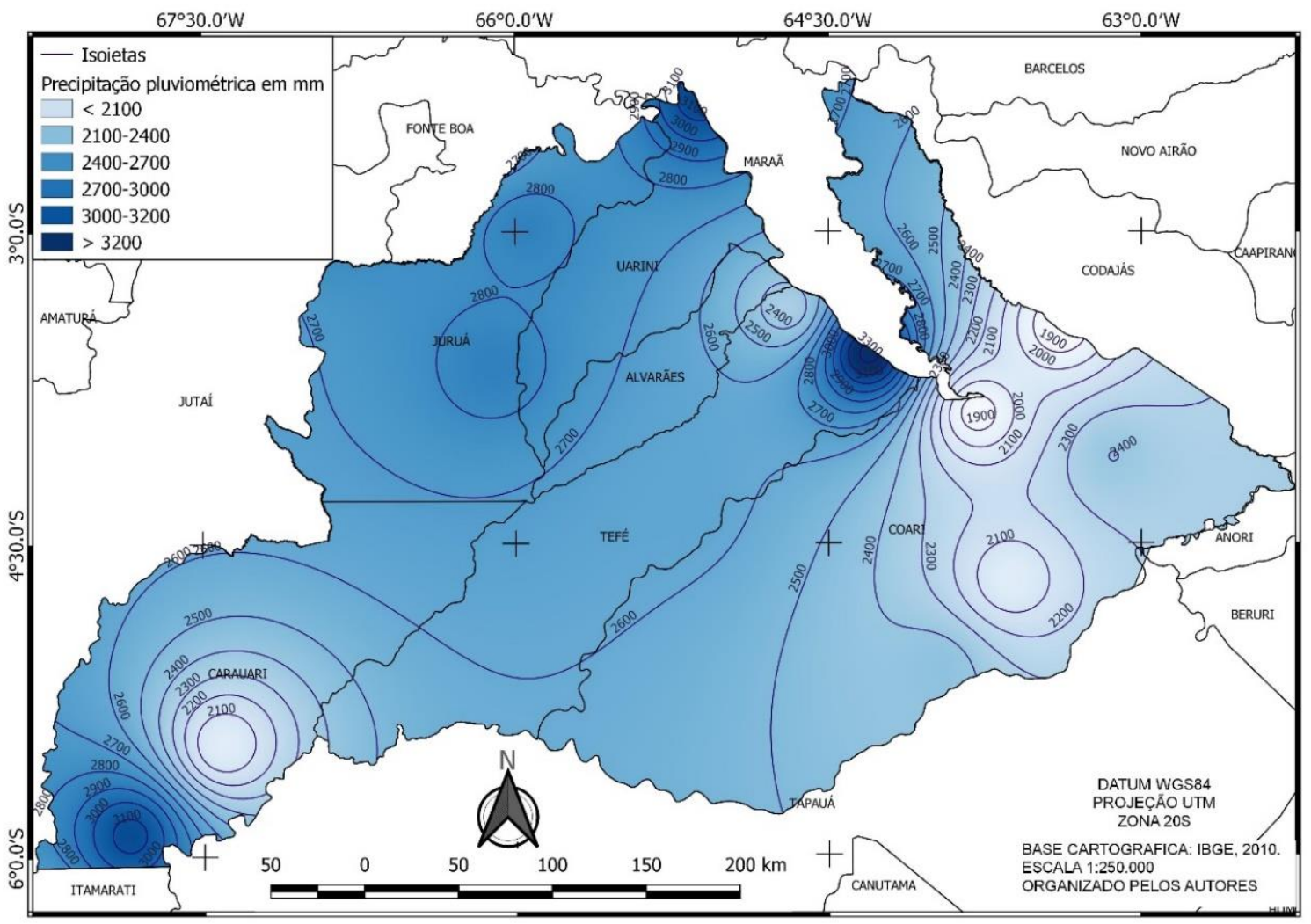

Fonte - Autores, 2018.

A partir dos dados de precipitação pluviométrica, foi aplicada a equação proposta por Lombardi Neto e Moldenhauer (1992), e estabelecida a classificação anual e mensal da erosividade da chuva na região do Médio Solimões, baseado na proposta de Carvalho (1994) que, com os valores em MJ mm ha-1 $\mathrm{h}^{-1}$ $\mathrm{ano}^{-1}$ e MJ mm ha-1 $\mathrm{h}^{-1}$ mês $^{-1}$, estabeleceu as classes: Muito baixa, Baixa, Média, Alta e Muito Alta (Quadro 1).

Quadro 1 - Classes de erosividade da chuva média anual e mensal.

\begin{tabular}{|c|c|c|}
\hline \multirow{2}{*}{ Classe de erosividade } & \multicolumn{2}{|c|}{ Valores de erosividade } \\
\hline & MJ mm ha- ${ }^{1}$ h - ${ }^{1}$ ano- ${ }^{1}$ & MJ mm ha- ${ }^{1} h-^{-1}$ mês- ${ }^{1}$ \\
\hline Muito baixa & $\mathrm{R}<2.500$ & $\mathrm{R}<250$ \\
\hline Baixa & $2.500<R<5.000$ & $250<R<500$ \\
\hline Média & $5.000<R<7.000$ & $500<\mathrm{R}<700$ \\
\hline Alta & $7.000<R<10.000$ & $700<R<1.000$ \\
\hline Muito alta & $R>10.000$ & $R>1.000$ \\
\hline
\end{tabular}

Fonte - Adaptado de Carvalho, 1994.

A distribuição sazonal da erosividade na área de estudo conforme Quadro 2, demonstrou que os meses de dezembro a maio apresentaram os maiores índices com valores entre 700 e $1900 \mathrm{MJ}$ mm ha-1 h${ }^{1}$ mês-1 ${ }^{1}$, sobretudo o mês de março que apresentou erosividade muito alta em todas estações, seguido pelo mês de abril. 
Quadro 2 - Classes de erosividade da chuva média mensal de janeiro a junho.

\begin{tabular}{|c|c|c|c|c|c|c|c|c|c|}
\hline \multirow{2}{*}{ ID } & \multirow{2}{*}{ ESTAÇÃO } & \multicolumn{2}{|c|}{ COORDENADAS } & \multicolumn{6}{|c|}{ Valores de erosividade (MJ mm ha- ${ }^{-1} \mathrm{~h}^{-1}$ mês- $\left.{ }^{-1}\right)$} \\
\hline & & W & s & JAN & FEV & MAR & $A B R$ & MAI & JUN \\
\hline 1 & Barreirinha & $66^{\circ} 27^{\prime} 46^{\prime \prime}$ & $02^{\circ} 06^{\prime} 59^{\prime \prime}$ & 1184,88 & 902,52 & 1262,37 & 1321,04 & 1360,26 & 859,71 \\
\hline 2 & Barro Alto & $63^{\circ} 47^{\prime} 09^{\prime \prime}$ & $03^{\circ} 52^{\prime} 30^{\prime \prime}$ & 1048,21 & 745,55 & 1309,42 & 806,01 & 854,96 & 272,66 \\
\hline 3 & Coari 3001 & $63^{\circ} 08^{\prime} 00^{\prime \prime}$ & $04^{\circ} 05^{\prime} 00^{\prime \prime}$ & 1366,42 & 1353,23 & 1770,97 & 1403,72 & 843,43 & 338,89 \\
\hline 4 & Colocação Caxias Novo & $68^{\circ} 59^{\prime} 54^{\prime \prime}$ & $05^{\circ} 22^{\prime} 51^{\prime \prime}$ & 1672,75 & 1293,89 & 1789,59 & 1218,03 & 713,62 & 451,47 \\
\hline 5 & Conceição & $68^{\circ} 39^{\prime} 48^{\prime \prime}$ & $04^{\circ} 53^{\prime} 48^{\prime \prime}$ & 1510,53 & 1203,41 & 1547,48 & 1538,2 & 825,2 & 392,13 \\
\hline 6 & Erunepé & $69^{\circ} 52^{\prime} 00^{\prime \prime}$ & $06^{\circ} 40^{\prime} 00^{\prime \prime}$ & 1436,15 & 1420,52 & 1406,23 & 1333,92 & 532,26 & 207,56 \\
\hline 7 & Envira & $70^{\circ} 01^{\prime} 21^{\prime \prime}$ & $07^{\circ} 25^{\prime} 41^{\prime \prime}$ & 1979,91 & 1925,52 & 1623,25 & 956,81 & 475,59 & 125,81 \\
\hline 8 & Espirito Santo & $67^{\circ} 34^{\prime} 00^{\prime \prime}$ & $02^{\circ} 45^{\prime} 00^{\prime \prime}$ & 1381,65 & 1000,46 & 1306,49 & 1164,97 & 994,62 & 538,64 \\
\hline 9 & Estirão da Santa Cruz & $65^{\circ} 12^{\prime} 06^{\prime \prime}$ & $04^{\circ} 17^{\prime} 32^{\prime \prime}$ & 1316,93 & 1249,31 & 1898,48 & 1352,06 & 857,49 & 406,31 \\
\hline 10 & Fonte Boa & $66^{\circ} 10^{\prime} 00^{\prime \prime}$ & $02^{\circ} 32^{\prime} 00^{\prime \prime}$ & 1001,58 & 745,45 & 1127,57 & 1315,92 & 1329,19 & 739,77 \\
\hline 11 & Forte Das Graças & $66^{\circ}$ 06' 11" & $03^{\circ} 38^{\prime} 29^{\prime \prime}$ & 1237,24 & 1396,67 & 2208,11 & 1234,41 & 1113,11 & 585,19 \\
\hline 12 & Foz Do Gregório & $70^{\circ} 39^{\prime} 00^{\prime \prime}$ & $06^{\circ} 48^{\prime} 00^{\prime \prime}$ & 843,08 & 1180,12 & 1180,87 & 759,84 & 524,81 & 291,43 \\
\hline 13 & Ipixuna & $71^{\circ} 41^{\prime} 03^{\prime \prime}$ & $07^{\circ} 03^{\prime} 03^{\prime \prime}$ & 1029,48 & 911,21 & 1282,49 & 972,44 & 542,31 & 314 \\
\hline 14 & Japura Acanaui & $66^{\circ} 36^{\prime} 00^{\prime \prime}$ & $01^{\circ} 49^{\prime} 15^{\prime \prime}$ & 1147,21 & 1026,5 & 1327,57 & 1630,76 & 1572,24 & 1030,4 \\
\hline 15 & Japura Villa Bittencourt & $69^{\circ} \quad 25^{\prime} 42^{\prime \prime}$ & $01^{\circ} 23^{\prime} 41^{\prime \prime}$ & 863,93 & 1025,33 & 1172,52 & 1368,64 & 1174,14 & 729,63 \\
\hline 16 & Jutica & $64^{\circ} 18^{\prime} 25^{\prime \prime}$ & $03^{\circ} 35^{\prime} 25^{\prime \prime}$ & 1610,23 & 1253,81 & 1701,65 & 1577,73 & 1253,41 & 717,83 \\
\hline 17 & Liberdade & $63^{\circ} 23^{\prime} 32^{\prime \prime}$ & $03^{\circ} 27^{\prime} 23^{\prime \prime}$ & 889,41 & 755,86 & 1327,52 & 816,86 & 865,84 & 275,89 \\
\hline 18 & Mangueira & $68^{\circ} 50^{\prime} 00^{\prime \prime}$ & $01^{\circ} 46^{\prime} 00^{\prime \prime}$ & 988,87 & 1388,86 & 1874,32 & 1022,65 & 1063,4 & 609,24 \\
\hline 19 & Maraas & $65^{\circ} 35^{\prime} 26^{\prime \prime}$ & $01^{\circ} 51^{\prime} 40^{\prime \prime}$ & 737,06 & 835,11 & 1264,41 & 1081,03 & 1203,93 & 961,99 \\
\hline 20 & Marimari & $67^{\circ} 24^{\prime} 21^{\prime \prime}$ & $05^{\circ} 27^{\prime} 39^{\prime \prime}$ & 1074,92 & 994,3 & 1201,69 & 968,84 & 569,1 & 253,45 \\
\hline 21 & Martirio & $65^{\circ} 56^{\prime} 31^{\prime \prime}$ & $02^{\circ} 58^{\prime} 52^{\prime \prime}$ & 1326,11 & 946,5 & 1463,03 & 1472,05 & 1252,59 & 808,64 \\
\hline 22 & Porto Antunes & $66^{\circ} 56^{\prime} 57^{\prime \prime}$ & $02^{\circ} 53^{\prime} 25^{\prime \prime}$ & 1478 & 959,23 & 1462,97 & 1349,02 & 1150,31 & 788,96 \\
\hline 23 & Porto Seguro & $\begin{array}{ll}67^{\circ} & 29^{\prime} 20^{\prime \prime} \\
\end{array}$ & $03^{\circ} 20^{\prime} 14^{\prime \prime}$ & 1134,57 & 851,74 & 1170,99 & 1341,88 & 1101,94 & 557,95 \\
\hline 24 & Santos Dumont & $68^{\circ} 14^{\prime} 38^{\prime \prime}$ & $06^{\circ} 26^{\prime} 30^{\prime \prime}$ & 1697,99 & 1578,53 & 1687,56 & 1095,81 & 546,72 & 231,82 \\
\hline 25 & São Pedro Maraa & $65^{\circ} 07^{\prime} 00^{\prime \prime}$ & $02^{\circ} 21^{\prime} 00^{\prime \prime}$ & 928,82 & 936,98 & 1446,73 & 1479,6 & 1269,73 & 915,26 \\
\hline 26 & Seringal Boa Fé & $72^{\circ} 20^{\prime} 01^{\prime \prime}$ & $07^{\circ} 14^{\prime} 09^{\prime \prime}$ & 1268,58 & 1136,47 & 1293,05 & 1273,77 & 618,92 & 203,94 \\
\hline 27 & Seringal Moreira & $63^{\circ} 59^{\prime} 05^{\prime \prime}$ & $05^{\circ} 06^{\prime} 33^{\prime \prime}$ & 1270,94 & 1458,77 & 1550,77 & 1511,96 & 771,7 & 306,63 \\
\hline 28 & Seringal St. Amaro & $70^{\circ} 59^{\prime} 00^{\prime \prime}$ & $07^{\circ} 16^{\prime} 00^{\prime \prime}$ & 1379,95 & 1296,9 & 1790,47 & 1058,69 & 729,53 & 319,28 \\
\hline 29 & Soledade & $69^{\circ} 08^{\prime} 00^{\prime \prime}$ & $06^{\circ} 37^{\prime} 00^{\prime \prime}$ & 1806,83 & 1649,08 & 1587,9 & 1186,77 & 757,28 & 400,41 \\
\hline 30 & Tefé INMET & $64^{\circ} \quad 42^{\prime} 00^{\prime \prime}$ & $03^{\circ} 22^{\prime} 00^{\prime \prime}$ & 1333,75 & 1089,25 & 1353,6 & 1362,84 & 1043,74 & 448,13 \\
\hline 31 & Vista Alegre & $63^{\circ} \quad 37^{\prime} 40^{\prime \prime}$ & $04^{\circ} 40^{\prime} 21^{\prime \prime}$ & 898,92 & 1017,33 & 1158,8 & 1170,01 & 583,43 & 369,15 \\
\hline 32 & Xibaua & $67^{\circ} 51^{\prime} 25^{\prime \prime}$ & $05^{\circ} 53^{\prime} 37^{\prime \prime}$ & 1729,53 & 1398,18 & 1986,15 & 1050,02 & 832,99 & 569,59 \\
\hline & & CLASSES DE & EROSIVIDADE & Muito alta & Alta & Média & Muito baixa & Baixa & \\
\hline
\end{tabular}

Fonte - Hidroweb - ANA, 2015. Organizado pelos autores, 2019.

Nos meses de junho a novembro os índices de erosividade, variaram entre 100 e $1300 \mathrm{MJ}$ mm ha-1 h${ }^{1}$ mês-1 ${ }^{1}$, tendo uma relação direta com a precipitação pluviométrica da região, observando-se nos meses de julho e agosto Erosividade Muito Baixa em várias estações.

Quanto a distribuição espacial e temporal da erosividade nos municípios do Médio Solimões, observouse que no mês de janeiro, os maiores índices de erosividade se concentraram na porção norte do

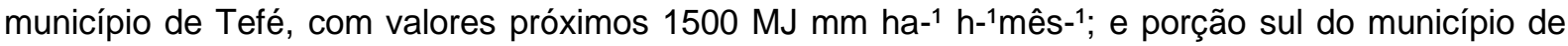
Carauari com valores próximos $1700 \mathrm{MJ} \mathrm{mm}$ ha- ${ }^{-1} \mathrm{~h}-{ }^{-1} \mathrm{mês}^{-1}$.

Os menores índices de erosividade em janeiro, a saber, entre 800 e 1100, foram observados na porção norte dos municípios de Juruá e Uarini e grande parte do município de Coari.

Em fevereiro, os maiores índices de erosividade foram observados na porção central de Juruá e sul de

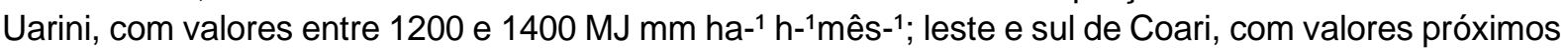
$1400 \mathrm{MJ}$ mm ha- ${ }^{-1} \mathrm{~h}^{-1} \mathrm{mês}^{-1}$; município de Tefé, com valores próximos $1500 \mathrm{MJ} \mathrm{mm}^{\mathrm{ha}}{ }^{-1} \mathrm{~h}^{-1} \mathrm{mês}^{-1}$; e porção sul do município de Carauari, com valores próximos $1200 \mathrm{MJ}$ mm ha- ${ }^{-1}$ - ${ }^{-1} \mathrm{mês}^{-1}$. 
Quadro 3 - Classes de erosividade da chuva média mensal de julho a dezembro.

\begin{tabular}{|c|c|c|c|c|c|c|c|c|c|}
\hline \multirow{2}{*}{ ID } & \multirow{2}{*}{ ESTAÇÃO } & \multicolumn{2}{|c|}{ COORDENADAS } & \multicolumn{6}{|c|}{ Valores de erosividade ( $\mathrm{MJ} \mathrm{mm} \mathrm{ha-1} \mathrm{h}^{-1}$ mês- ${ }^{-1}$ ) } \\
\hline & & W & s & JUL & AGO & SET & OUT & NOV & $\mathrm{DEZ}$ \\
\hline 1 & Barreirinha & $66^{\circ} 27^{\prime} 46^{\prime \prime}$ & $02^{\circ} 06^{\prime} 59^{\prime \prime}$ & 734,44 & 582,64 & 533,28 & 790,19 & 913,55 & 1329,42 \\
\hline 2 & Barro Alto & $63^{\circ} 47^{\prime} 09^{\prime \prime}$ & $03^{\circ} 52^{\prime} 30^{\prime \prime}$ & 176,21 & 108,7 & 276,38 & 345,43 & 686,8 & 1098,77 \\
\hline 3 & Coari 3001 & $63^{\circ} 08^{\prime} 00^{\prime \prime}$ & $04^{\circ} 05^{\prime} 00^{\prime \prime}$ & 151,46 & 139,85 & 198,55 & 465,51 & 796,28 & 1051,94 \\
\hline 4 & Colocação Caxias Novo & $68^{\circ} 59^{\prime} 54^{\prime \prime}$ & $05^{\circ} 22^{\prime} 51^{\prime \prime}$ & 242,91 & 246,02 & 404,28 & 727,17 & 996,32 & 1332,44 \\
\hline 5 & Conceição & $68^{\circ} 39^{\prime} 48^{\prime \prime}$ & $04^{\circ} 53^{\prime} 48^{\prime \prime}$ & 219,02 & 188,75 & 369,79 & 619,62 & 919,96 & 1231,41 \\
\hline 6 & Eirunepé & $69^{\circ} 52^{\prime} 00^{\prime \prime}$ & $06^{\circ} 40^{\prime} 00^{\prime \prime}$ & 108,44 & 163,22 & 390,23 & 709,04 & 839,03 & 1361,24 \\
\hline 7 & Envira & $70^{\circ} 01^{\prime} 21^{\prime \prime}$ & $07^{\circ} 25^{\prime} 41^{\prime \prime}$ & 59,33 & 122,77 & 264,01 & 844,32 & 1000,1 & 1650,32 \\
\hline 8 & Espirito Santo & $67^{\circ} 34^{\prime} 00^{\prime \prime}$ & $02^{\circ} 45^{\prime} 00^{\prime \prime}$ & 478,58 & 323,83 & 438,88 & 631,35 & 798,26 & 944,12 \\
\hline 9 & Estirão da Santa Cruz & $65^{\circ} 12^{\prime} 06^{\prime \prime}$ & $04^{\circ} 17^{\prime} 32^{\prime \prime}$ & 314,17 & 242,23 & 377,09 & 522,91 & 553,39 & 1235,9 \\
\hline 10 & Fonte Boa & $66^{\circ} 10^{\prime} 00^{\prime \prime}$ & $02^{\circ} 32^{\prime} 00^{\prime \prime}$ & 575,29 & 321,55 & 384,01 & 490,62 & 629,64 & 821,19 \\
\hline 11 & Forte Das Graças & $66^{\circ} 06^{\prime} 11^{\prime \prime}$ & $03^{\circ} 38^{\prime} 29^{\prime \prime}$ & 319,09 & 394,2 & 508,16 & 546,46 & 703,17 & 684,43 \\
\hline 12 & Foz Do Gregório & $70^{\circ} 39^{\prime} 00^{\prime \prime}$ & $06^{\circ} 48^{\prime} 00^{\prime \prime}$ & 180,16 & 224,73 & 467,1 & 723,42 & 799,57 & 895,84 \\
\hline 13 & Ipixuna & $71^{\circ} 41^{\prime} 03^{\prime \prime}$ & $07^{\circ} 03^{\prime} 03^{\prime \prime}$ & 214,4 & 235,47 & 398,04 & 867,64 & 984,83 & 1342,56 \\
\hline 14 & Japura Acanaui & $66^{\circ} 36^{\prime} 00^{\prime \prime}$ & $01^{\circ} 49^{\prime} 15^{\prime \prime}$ & 754,69 & 493,48 & 514,71 & 454,9 & 623,11 & 843,07 \\
\hline 15 & Japura Villa Bittencourt & $69^{\circ} 25^{\prime} 42^{\prime \prime}$ & $01^{\circ} 23^{\prime} 41^{\prime \prime}$ & 668,95 & 712,03 & 465,09 & 771,87 & 583,08 & 738,22 \\
\hline 16 & Jutica & $64^{\circ} 18^{\prime} 25^{\prime \prime}$ & $03^{\circ} 35^{\prime} 25^{\prime \prime}$ & 389,55 & 339,6 & 483,9 & 833,41 & 936,32 & 1133,1 \\
\hline 17 & Liberdade & $63^{\circ} 23^{\prime} 32^{\prime \prime}$ & $03^{\circ} 27^{\prime} 23^{\prime \prime}$ & 177,37 & 110,2 & 254,82 & 350,2 & 688,49 & 1104,89 \\
\hline 18 & Mangueira & $68^{\circ} 50^{\prime} 00^{\prime \prime}$ & $01^{\circ} 46^{\prime} 00^{\prime \prime}$ & 572,54 & 497,97 & 680,12 & 949,1 & 896,78 & 1287,59 \\
\hline 19 & Maraas & $65^{\circ} 35^{\prime} 26^{\prime \prime}$ & $01^{\circ} 51^{\prime} 40^{\prime \prime}$ & 592,67 & 403,27 & 304,19 & 303,13 & 435,81 & 723,91 \\
\hline 20 & Marimari & $67^{\circ} 24^{\prime} 21^{\prime \prime}$ & $05^{\circ} 27^{\prime} 39^{\prime \prime}$ & 122,72 & 155,11 & 288,74 & 596,5 & 916,77 & 1117,8 \\
\hline 21 & Martirio & $65^{\circ} 56^{\prime} 31^{\prime \prime}$ & $02^{\circ} 58^{\prime} 52^{\prime \prime}$ & 571,6 & 464,3 & 382,46 & 481,54 & 651,46 & 832,9 \\
\hline 22 & Porto Antunes & $66^{\circ} 56^{\prime} 57^{\prime \prime}$ & $02^{\circ} 53^{\prime} 25^{\prime \prime}$ & 490,53 & 417,25 & 388,1 & 556,86 & 741,78 & 861,34 \\
\hline 23 & Porto Seguro & $67^{\circ} 29^{\prime} 20^{\prime \prime}$ & $03^{\circ} 20^{\prime} 14^{\prime \prime}$ & 430,63 & 345,69 & 394,66 & 643,36 & 665,57 & 854,17 \\
\hline 24 & Santos Dumont & $68^{\circ} 14^{\prime} 38^{\prime \prime}$ & $06^{\circ} 26^{\prime} 30^{\prime \prime}$ & 102,52 & 139,49 & 181,08 & 846,76 & 820,13 & 1354,84 \\
\hline 25 & São Pedro Maraa & $65^{\circ} 07^{\prime} 00^{\prime \prime}$ & $02^{\circ} 21^{\prime} 00^{\prime \prime}$ & 662,6 & 481,84 & 608,04 & 819,77 & 815,18 & 1031,27 \\
\hline 26 & Seringal Boa Fé & $72^{\circ} 20^{\prime} 01^{\prime \prime}$ & $07^{\circ} 14^{\prime} 09^{\prime \prime}$ & 118,04 & 117,84 & 320,38 & 674,77 & 1065,53 & 1096,73 \\
\hline 27 & Seringal Moreira & $63^{\circ} 59^{\prime} 05^{\prime \prime}$ & $05^{\circ} 06^{\prime} 33^{\prime \prime}$ & 227,32 & 147,41 & 312,26 & 489,58 & 778,38 & 1041,01 \\
\hline 28 & Seringal St. Amaro & $70^{\circ} 59^{\prime} 00^{\prime \prime}$ & $07^{\circ} 16^{\prime} 00^{\prime \prime}$ & 119,15 & 143,67 & 317,61 & 731,52 & 793,26 & 1290,48 \\
\hline 29 & Soledade & $69^{\circ} 08^{\prime} 00^{\prime \prime}$ & $06^{\circ} 37^{\prime} 00^{\prime \prime}$ & 149,77 & 212,03 & 341,84 & 1033,76 & 1289,62 & 1441,15 \\
\hline 30 & Tefé INMET & $64^{\circ} \quad 42^{\prime} 00^{\prime \prime}$ & $03^{\circ} 22^{\prime} 00^{\prime \prime}$ & 270,18 & 196,32 & 280,33 & 493,95 & 603,73 & 811,8 \\
\hline 31 & Vista Alegre & $63^{\circ} \quad 37^{\prime} 40^{\prime \prime}$ & $04^{\circ} 40^{\prime} 21^{\prime \prime}$ & 235,03 & 254,86 & 318,95 & 425,28 & 772,5 & 845,26 \\
\hline \multirow[t]{2}{*}{32} & Xibaua & $67^{\circ} 51^{\prime} 25^{\prime \prime}$ & $05^{\circ} 53^{\prime} 37^{\prime \prime}$ & 108,31 & 168,02 & 289,3 & 1193,82 & 1346,5 & 1589,1 \\
\hline & & CLASSES DE & EROSIVIDADE & Muito alta & Alta & Média & Muito baixa & Baixa & \\
\hline
\end{tabular}

Fonte - Hidroweb - ANA, 2015. Organizado pelos autores, 2019.

Os menores índices de erosividade em fevereiro, próximos a $900 \mathrm{MJ} \mathrm{mm}$ ha- ${ }^{-1} \mathrm{~h}^{-1} \mathrm{mês}^{-1}$, foram observados na porção norte dos municípios de Juruá, Uarini e de Coari.

No mês de março, verificou-se o aumento dos índices de erosividade, com valores próximos a $2200 \mathrm{MJ}$ mm ha-1 h-1 mês-1 ${ }^{-1}$ observados na porção central de Juruá e sul de Uarini; valores próximos 1900 MJ $\mathrm{mm}$ ha-1 h-1 mês- $^{-1}$ na porção central do município de Tefé; e na porção sul do município de Carauari, valores próximos 2000 MJ mm ha- ${ }^{-1} \mathrm{~h}^{-1}$ mês- $^{-1}$.

Em março, os menores índices de erosividade, associados a $1200 \mathrm{MJ} m \mathrm{~m}$ ha- ${ }^{1} \mathrm{~h}^{-1} \mathrm{mês}^{-1}$, foram observados na porção leste dos municípios de Carauari e em grande parte do município de Coari, além da porção norte do recorte espacial analisado.

No mês de abril, verificaram-se índices de erosividade com valores próximos a $1500 \mathrm{MJ} \mathrm{mm} \mathrm{ha-}^{-1} \mathrm{~h}-$ ${ }^{1}$ mês-1 observados na porção sudeste de Coari e nas porções norte de Juruá, Uarini e Tefé.

Os menores índices de erosividade, com valores inferiores a $1000 \mathrm{MJ} \mathrm{mm}$ ha- ${ }^{1} \mathrm{~h}^{-1} \mathrm{mês}^{-1}$, foram observados na porção sul do município de Carauari e norte do município de Coari (Figura 4). 
Figura 4 - Erosividade mensal das chuvas na região do Médio Solimões de janeiro a abril.

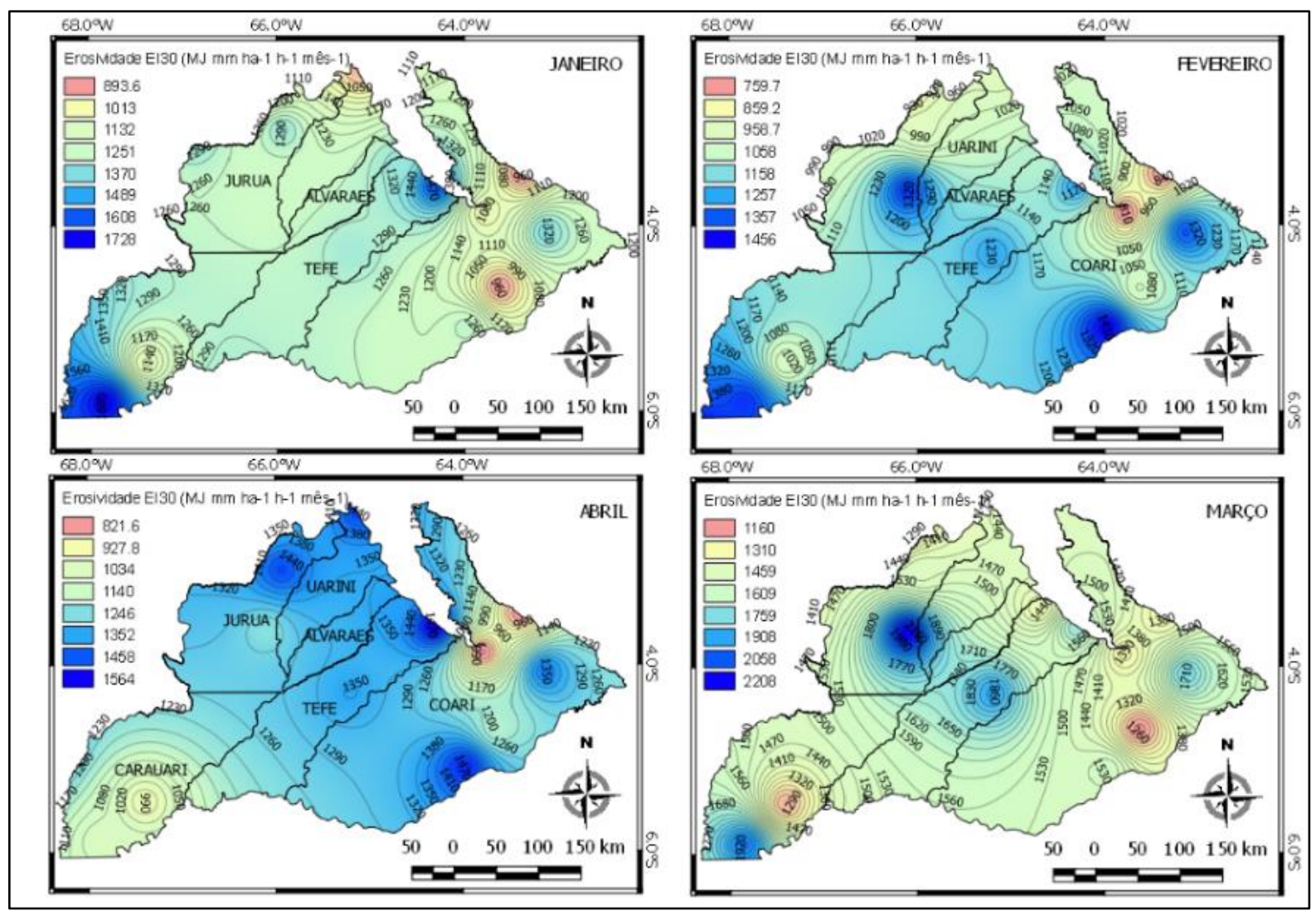

Fonte - Elaborado pelos autores, 2019.

Em maio, os maiores índices de erosividade, definidos como Muito Alta Erosividade, com valores próximos a $1300 \mathrm{MJ} \mathrm{mm}^{\text {ha- }}{ }^{-1} \mathrm{~h}^{-1} \mathrm{mês}^{-1}$, foram observados na porção norte dos municípios de Uarini, Alvarães, Tefé e Coari.

Por sua vez, os menores índices de erosividade, entre 500 e 700 MJ mm ha- ${ }^{-1}$ - $^{-1} \mathrm{mês}^{-1}$, definidos como Média Erosividade, foram observados na porção sudeste de Coari e sul de Carauari.

A partir do mês de junho, observa-se a diminuição dos índices de erosividade na região do Médio Solimões, onde os maiores índices foram de aproximadamente $900 \mathrm{MJ} \mathrm{mm} \mathrm{ha-1} \mathrm{h-1} \mathrm{mês}^{-1}$, definidos como Alta Erosividade, verificados nas porções norte dos municípios de Juruá e Uarini.

Verificou-se que os menores índices de erosividade, entre 250 e $350 \mathrm{MJ} \mathrm{mm}^{\text {ha- }}{ }^{-1} \mathrm{~h}^{-1} \mathrm{mês}^{-1}$, definidos como Baixa Erosividade, foram observados na maior porção o município de Coari e sul de Carauari.

No mês de julho, foi observado o menor índice de erosividade na região do Médio Solimões, de aproximadamente $100 \mathrm{MJ}$ mm ha- ${ }^{1} \mathrm{~h}^{-1} \mathrm{mês}^{-1}$, definido como Muito Baixa Erosividade, obedecendo a uma configuração de distribuição muito semelhante ao mês de junho, sobretudo, os menores índices são observados na porção sul do município de Carauari.

Os maiores índices verificados foram de aproximadamente $650 \mathrm{MJ} \mathrm{mm} \mathrm{ha-1} \mathrm{h}^{-1} \mathrm{mês}^{-1}$, definidos como Média Erosividade, verificados nas porções norte dos municípios de Juruá e Uarini.

No mês de agosto, são verificados os menores índices máximos de erosividade na região do Médio Solimões, de aproximadamente $470 \mathrm{MJ} \mathrm{mm}^{\text {ha- }}{ }^{-1} \mathrm{~h}^{-1} \mathrm{mês}^{-1}$. Agosto é o único mês em que os índices máximos são definidos como Baixa Erosividade. Esses valores são verificados nas porções norte dos municípios de Juruá e Uarini.

Os menores índices de erosividade são verificados na porção nordeste do município de Coari, de aproximadamente $110 \mathrm{MJ} \mathrm{mm}$ ha- ${ }^{-1} \mathrm{~h}^{-1} \mathrm{mês}^{-1}$, classificado como erosividade Muito Baixa (Figura 5). 
Figura 5 - Erosividade mensal das chuvas na região do Médio Solimões de maio a agosto.

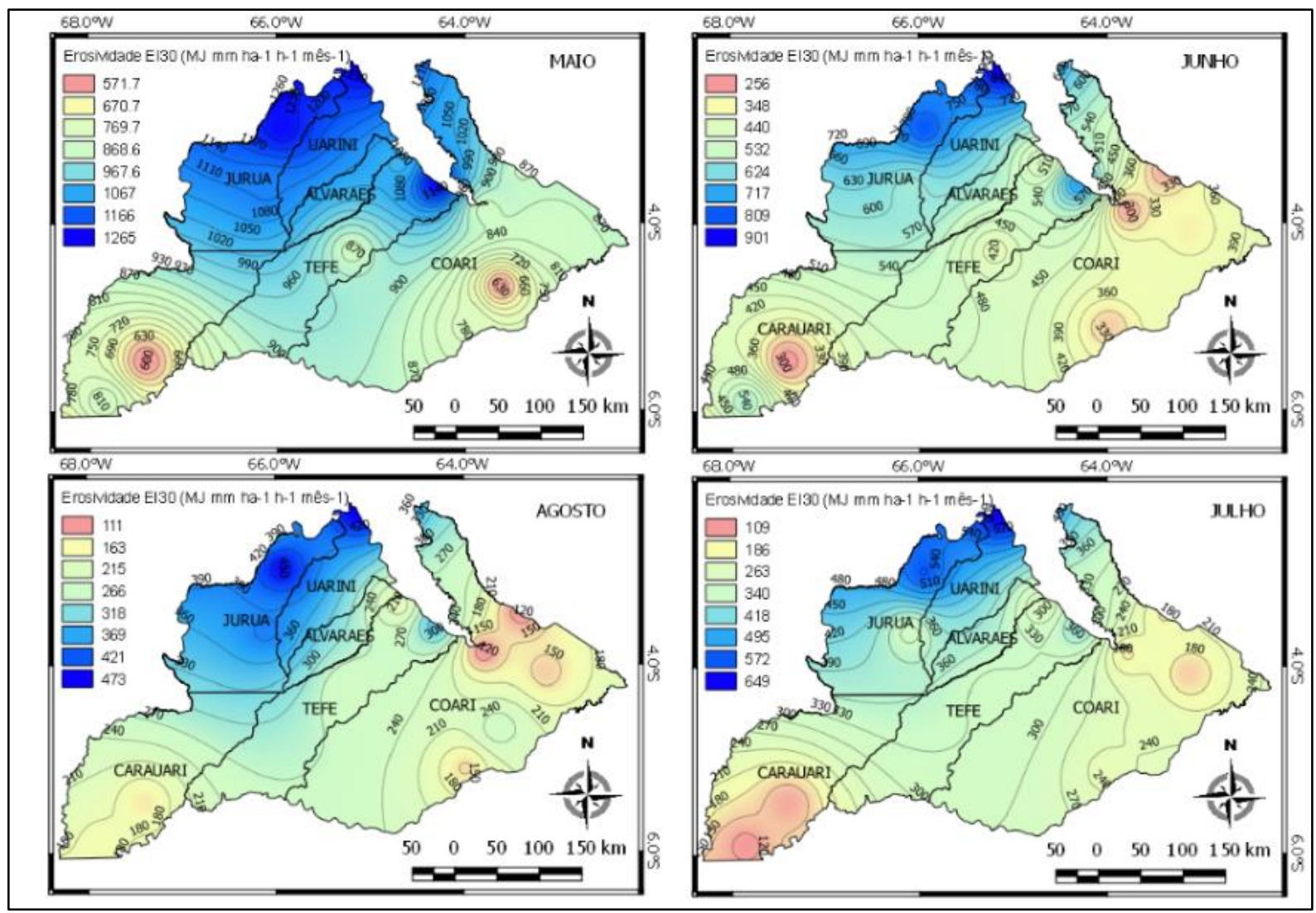

Fonte - Autores, 2019.

A partir do mês de setembro, verifica-se que os índices de erosividade na região do Médio Solimões voltam a aumentar gradativamente, apresentando os menores índices, com valores próximos a $200 \mathrm{MJ}$ $\mathrm{mm}$ ha- ${ }^{-1}$ h-1 ${ }^{-1} \mathrm{e}^{-1}$, classificado como erosividade Muito Baixa, observado na porção leste do município de Coari.

Quanto aos índices máximos, são verificados valores próximos a $600 \mathrm{MJ} \mathrm{mm}$ ha- ${ }^{-1} \mathrm{~h}-{ }^{-1} \mathrm{mês}^{-1}$, definidos como Média Erosividade, esses valores são verificados nas porções norte do município de Uarini.

O mês de outubro pode ser definido como o que precede o período chuvoso na região do Médio Solimões, observando-se índices de erosividade com valores próximos a $350 \mathrm{MJ}$ mm ha- ${ }^{-1} \mathrm{~h}^{-1} \mathrm{mês}-{ }^{-1}$. Há uma transição da erosividade Muito Baixa para Baixa, observado na porção leste do município de Coari.

No mês de outubro, há um aumento significativo dos índices máximos, comparado com mês anterior, pois são verificados valores próximos a $1200 \mathrm{MJ} \mathrm{mm}$ ha-1 $\mathrm{h}^{-1} \mathrm{mês}^{-1}$, definidos como erosividade Muito Alta, esses valores são verificados nas porções sul do município de Carauari.

No mês de novembro, observou-se os índices máximos próximos a $1400 \mathrm{MJ} m \mathrm{~m}$ ha-1 $\mathrm{h}^{-1} \mathrm{mês}^{-1}$, definidos como erosividade Muito Alta, esses valores são verificados nas porções sul do município de Carauari.

Os menores índices de erosividade em novembro, chegaram a valores próximos a $550 \mathrm{MJ} m \mathrm{~m}$ ha- ${ }^{1} \mathrm{~h}$ ${ }^{1}$ mês- $^{1}$, definido como erosividade média, observado na porção central do município de Tefé (Figura 6). 
Figura 6 - Erosividade mensal das chuvas na região do Médio Solimões de setembro a dezembro.

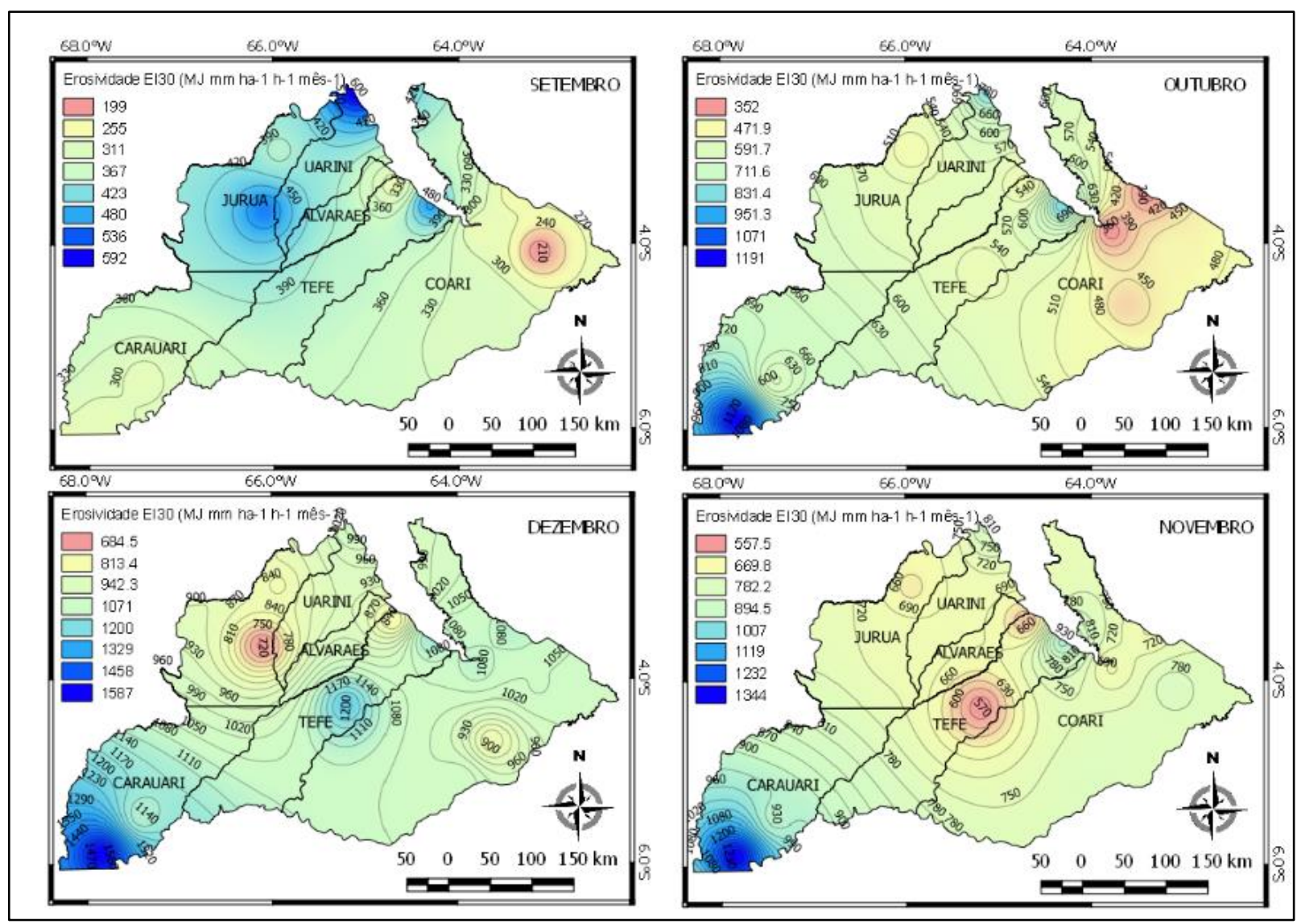

Fontes - autores, 2019.

Dezembro é considerado o início do período chuvoso na região, apresentando índices máximos próximos a $1600 \mathrm{MJ} \mathrm{mm}^{\text {ha- }}{ }^{-1} \mathrm{~h}^{-1} \mathrm{mês}^{-1}$, definidos como erosividade Muito Alta, esses valores são verificados nas porções sul do município de Carauari.

Observa-se também o aumento dos menores índices de erosividade em dezembro, que apresentou valores próximos a $690 \mathrm{MJ} \mathrm{mm}_{\text {ha- }}{ }^{-1} \mathrm{~h}^{-1} \mathrm{mês}^{-1}$, definido como erosividade Média, observado na porção leste do município de Juruá e sul de Uarini.

A média da Erosividade anual, das estações analisadas correspondeu a 10.103,34 MJ mm ha- ${ }^{-1}{ }^{-1}$ ano${ }^{1}$, classificada segundo Carvalho (1994), como Erosividade Muito Alta, $\mathrm{R}>10.000 \mathrm{MJ} \mathrm{mm}^{\mathrm{ha}} \mathrm{-}^{1} \mathrm{~h}^{-1}$ ano1. Assim, 16 estações, ou seja, $50 \%$ das estações analisadas, apresentaram índices de erosividade acima da média (Figura 7).

Quanto à distribuição espacial da Erosividade Anual na Região do Médio Solimões, os menores índices $<7.200$ a $8.200 \mathrm{MJ} \mathrm{mm} \mathrm{ha-}^{-1} \mathrm{~h}^{-1}$ ano- ${ }^{-1}$, foram observados a leste e a sudoeste da área de estudo, nas porções nordeste-sudeste do município de Coari e centro-sul de Carauari.

Os maiores índices de erosividade foram observados na porção norte do município de Tefé e porção sul do município de Carauari, com valores próximos superiores a $12.000 \mathrm{MJ} m \mathrm{~m} \mathrm{ha-}{ }^{-1} \mathrm{~h}^{-1}{ }^{1}$ no-1. . Na maior parte, verificou-se o predomínio de valores próximos da Média da erosividade anual, com valores próximos a $10.000 \mathrm{MJ} \mathrm{mm} \mathrm{ha-1} \mathrm{h}^{-1}{ }^{\text {ano- }}{ }^{-1}$ (Figura 8). 
Figura 7 - Erosividade anual das chuvas na região do Médio Solimões de 1992-2012.

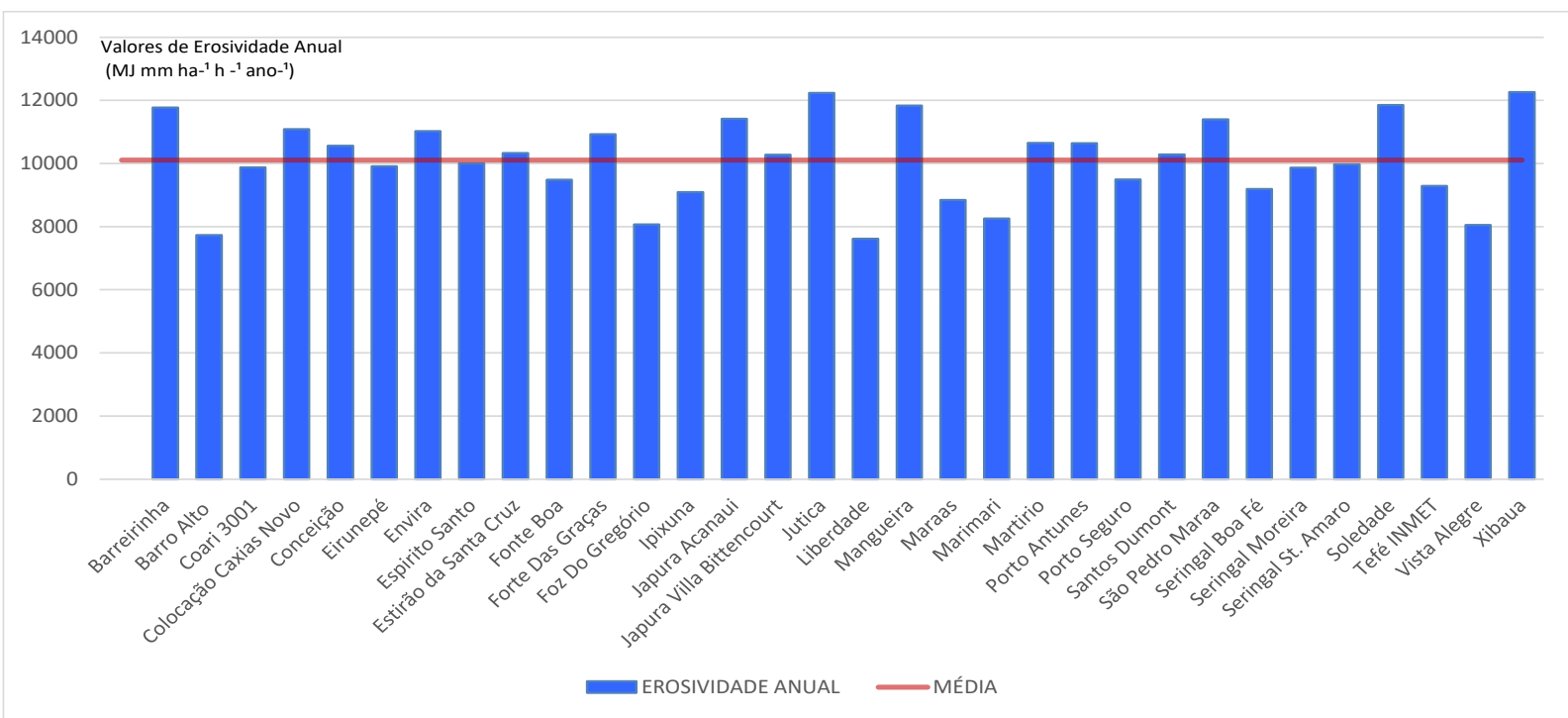

Fonte - Hidroweb - ANA, 2015. Organizado pelos autores, 2019.

Figura 8 - Erosividade anual das chuvas na região do Médio Solimões.

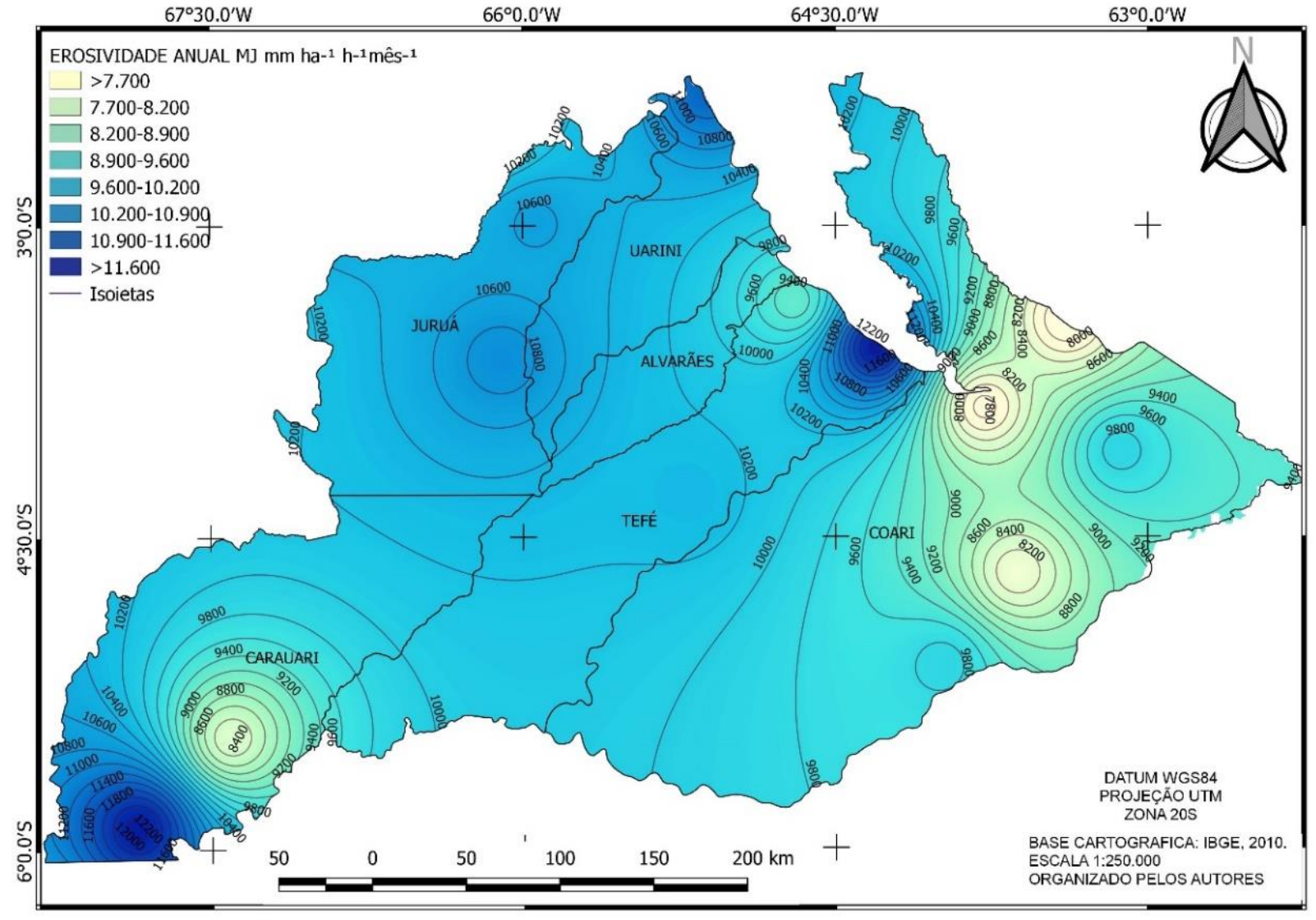

Fonte - Hidroweb - ANA, 2015. Organizado pelos autores, 2019.

A distribuição das classes de erosividade Alta foi verificada em aproximadamente $80 \%$ do município de Coari, nas porções norte de Tefé e Alvarães e centro-sul do Carauari e sul de Tefé (Figura 9). 
Figura 9 - Erosividade anual das chuvas na região do Médio Solimões.

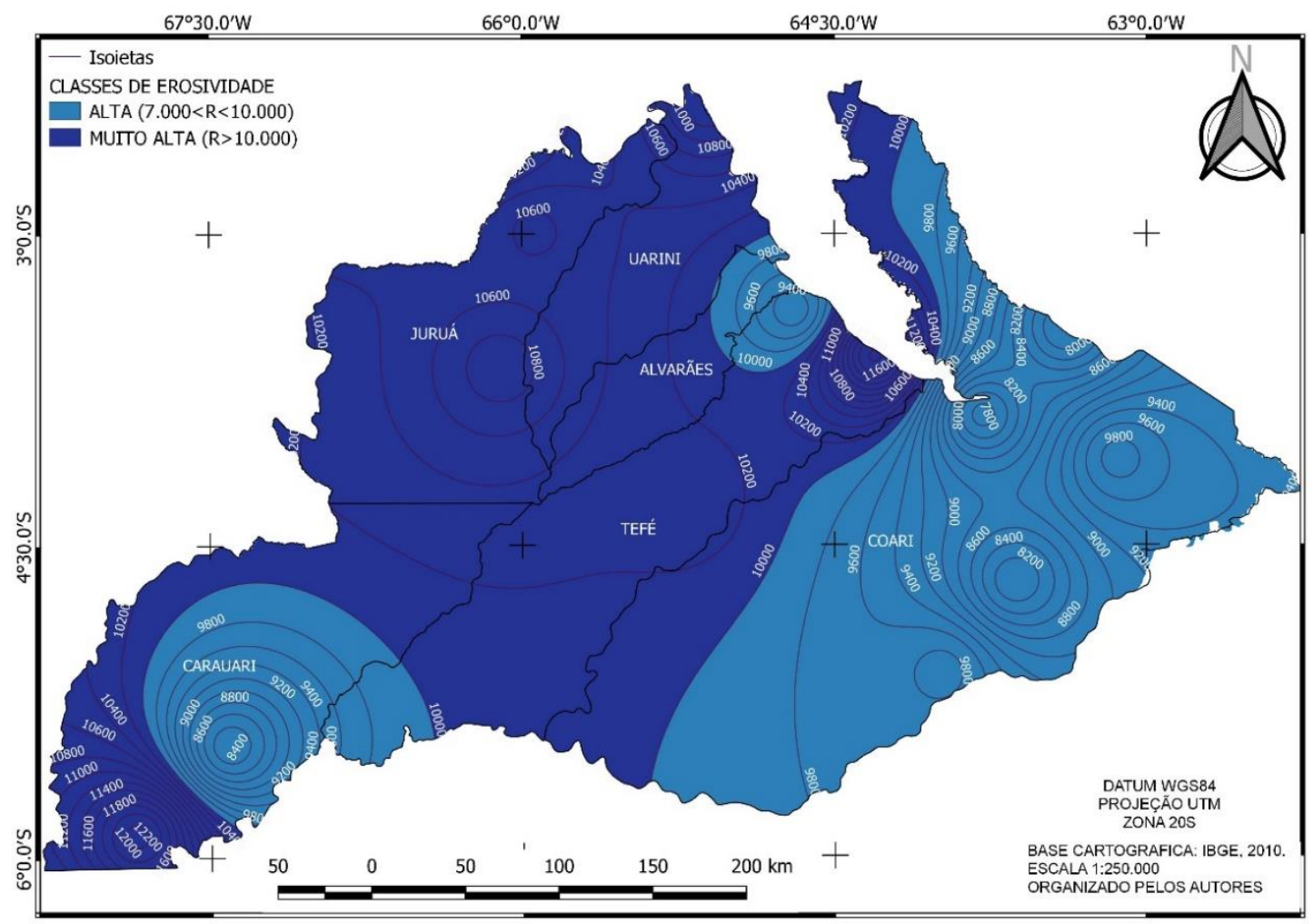

Fonte - Hidroweb - ANA, 2015. Organizado pelos autores, 2019.

A classe de erosividade Muito Alta compreendeu $56 \%$ da área de estudo, abrangendo porções significativas do município de Tefé e Alvarães, a totalidade dos municípios de Uarini e Juruá, além das porções ao norte e sul de Carauari (Figura 10).

Figura 10 - Classes de Erosividade anual das chuvas na região do Médio Solimões.

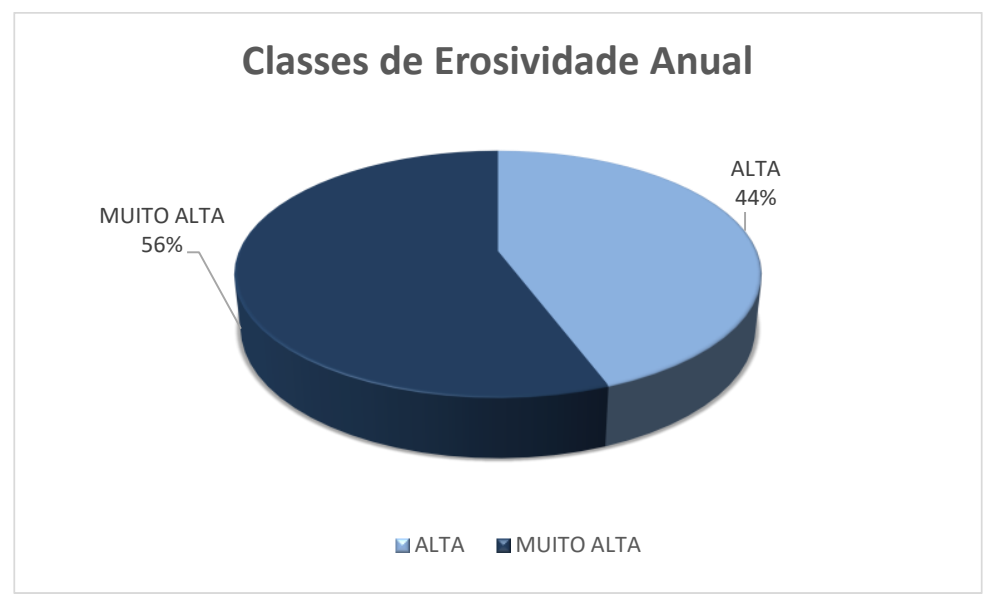

Fonte - Organizado pelos autores, 2019.

A partir dos resultados apresentados, é possível considerar que a erosividade é uma variável importante quando analisada de modo integrado aos condicionantes físicos-naturais, como solos que predominam na região do Médio Solimões. Destaca-se que o cálculo utilizado para se definir as classes de erosividade considera-se apenas a variável de precipitação pluviométrica, aplicada às equações para estimar seu papel no desencadeamento dos processos erosivos. 
Crepani et al (2008) e Ross (2008), consideram a erodibilidade de solos argissolos amarelo-vermelhos (classificados anteriormente como podzólicos amarelo-vermelhos) como Moderado e, os plintossolos, neossolos flúvicos, e gleissolos como Muito Alta.

Assim, os altos valores de erosividade e erodibilidade associados aos processos de apropriação da natureza, os quais substituem áreas de florestas primárias por usos da terra (como pecuária e agricultura), têm um impacto negativo, pois essa ação pode potencializar os processos de degradação ambiental com a intensificação de processos erosivos na região.

Segundo o PRODES - Projeto de Monitoramento por Satélites do Desmatamento na Amazônia Legal (2018), os municípios do Médio Solimões investigados na presente pesquisa, mostraram aumento gradativo do desmatamento a partir dos anos 2000, 2010 e 2017 (Figura 11).

Figura 11 - Desmatamento em municípios da região do Médio Solimões.

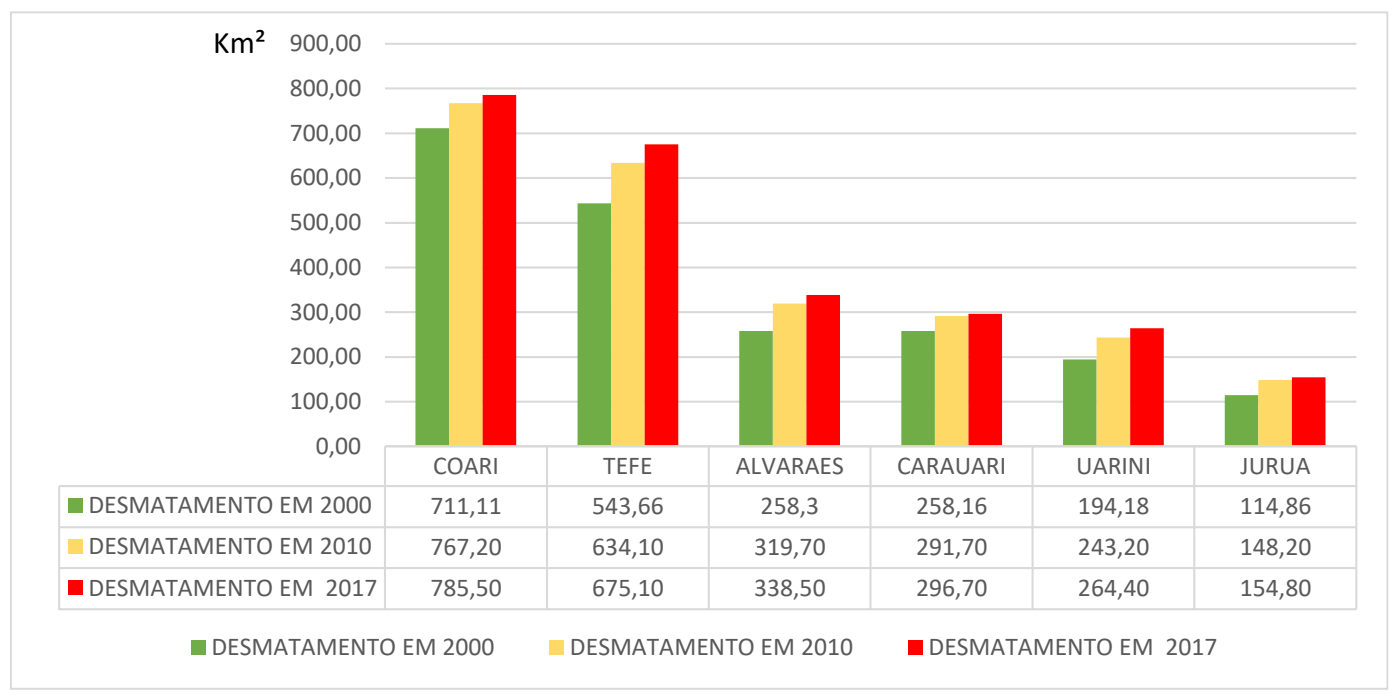

Fonte - PRODES, 2018. Organizado pelos autores, 2019.

Analisando os totais das áreas desmatadas entre 2000 a 2017 por município, verificou-se uma tendência crescente do aumento do desmatamento na região, observando-se um acréscimo de 434,73 $\mathrm{km}^{2}$, ou seja, mais de $20 \%$ da área foi desmatada no período (Figura 12).

Figura 12 - Desmatamento em municípios da região do Médio Solimões.

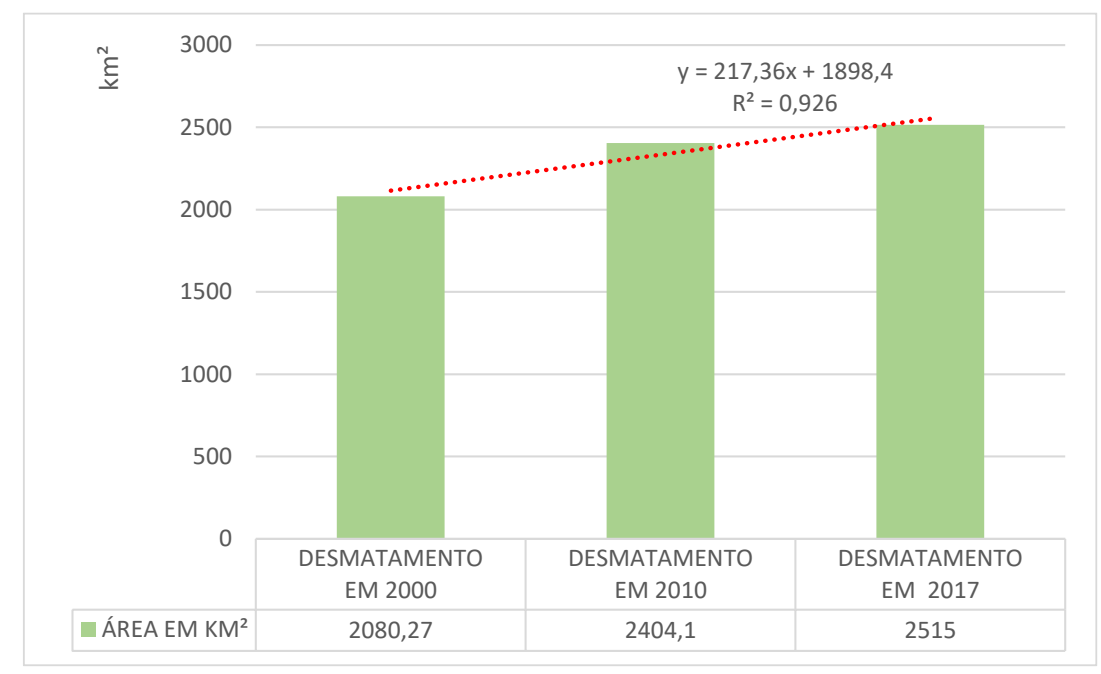

Fonte - PRODES, 2018. Organizado pelos autores, 2019. 
Desse modo, a Figura 13 ilustra a intensificação de processo erosivos lineares na área estudada, resultados da associação das classes de erosividade anual alta e muito alta, em decorrência dos fatores naturais e do uso da terra com predomínio de queimadas e desmatamento.

Figura 13 - Áreas de desmatamento no município de Tefé, Médio Solimões.

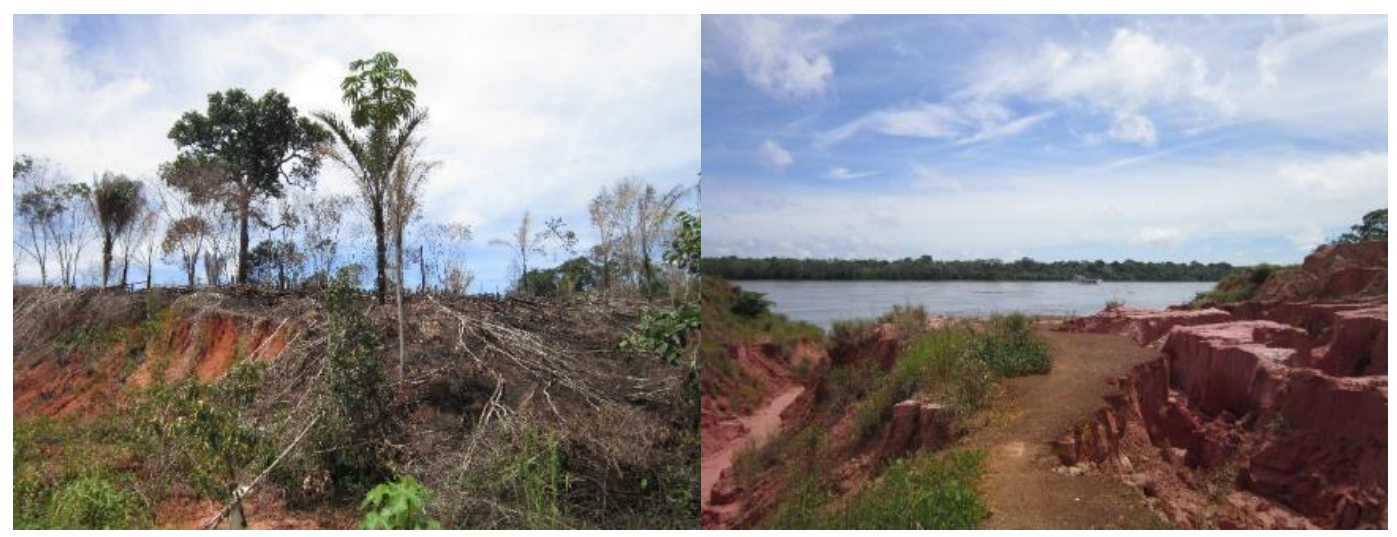

Fonte - Autores, 2016.

\section{CONSIDERAÇÕES FINAIS}

Os índices de erosividade mensal na região do Médio Solimões apresentam uma sazonalidade que acompanha os valores da precipitação pluviométrica na região, em que o predomínio dos maiores índices de erosividade, superiores a $700 \mathrm{MJ} \mathrm{mm} \mathrm{ha-}^{-1} \mathrm{~h}{ }^{-1}$ mês-1 correspondem às classes Muito Alta e Alta, observados entre os meses de dezembro a maio.

A partir do mês de junho ao mês de setembro, observa-se a diminuição dos índices mensais de erosividade, predominando as classes Baixa e Muito baixa, com valores inferiores a $500 \mathrm{MJ} m \mathrm{~m}$ ha-1 $\mathrm{h}$ -1 mês-1.

Nos meses de outubro e novembro os índices de erosividade voltam a aumentar, caracterizando-se como uma transição entre período seco e chuvoso na região do Médio Solimões.

No tocante dos índices de erosividade anual, predomina na região do Médio Solimões valores superiores a $7000 \mathrm{MJ} \mathrm{mm} \mathrm{ha-1} \mathrm{h}^{-1}$ ano-1, correspondendo às classes Muito Alta e Alta.

A partir de uma perspectiva de análise integrada das variáveis, os resultados alcançados sobre a erosividade na região do Médio Solimões apontam para importância da manutenção das áreas de florestas, visto que sua associação com as classes de erosividade e com os tipos de solos podem potencializar o desencadeamento de processos erosivos intensos como erosão em sulcos e voçorocamento.

Enfatiza-se que o auxílio de ferramentas de Sistemas de Informação Geográfica como técnicas geoestatísticas pode contribuir nas estimativas dos dados de erosividade para região analisada, visto suas particularidades, conforme destacou Silva (2004), uma vez que a região Amazônica apresenta uma escassa cobertura de estações meteorológica, refletindo em poucos estudos na região do Médio Solimões.

Ressalta-se a importância de pesquisas voltadas para o monitoramento e à análise climática na Amazônia brasileira, tendo em vista sua abrangência territorial, bem como a produção de dados confiáveis, que possibilitem diagnósticos seguros para se propor diretrizes que possam direcionar tomadas de decisão e políticas públicas voltadas às questões socioambientais na região.

\section{AGRADECIMENTOS}

Os autores agradecem ao Conselho Nacional de Desenvolvimento Científico e Tecnológico (CNPq), pelo suporte financeiro disponibilizado para pesquisa por meio do edital Universal 014/2013. A Fundação de Amparo à Pesquisa do Amazonas (FAPEAM), pelo apoio financeiro disponibilizado para pesquisa por meio do edital no 004/2017 PPP-FAPEAM. Ao Laboratório HIDROGEO - UFAM (Hidrogeografia, Climatologia e Analise Ambiental da Amazônia) - Universidade Federal do Amazonas. 


\section{REFERÊNCIAS}

ANA - AGÊNCIA NACIONAL DE ÁGUAS. (2015). HIDROWEB - Sistema de Informações Hidrológicas. Série histórica de dados de pluviométricos (on-line). Disponível em: http://hidroweb.ana.gov.br Acesso em: 12 de janeiro de 2015.

BERTONI, J.; LOMBARDI NETO, F. Conservação do solo. 4를. Edão Paulo: Ícone, 1999.

CAMARGO, E. C. G. et al. Análise Espacial de Superfícies. In: DRUCK, S.; CARVALHO, M.S.; CÂMARA, G.; MONTEIRO, A.V.M. (Eds.) Análise Espacial de Dados Geográficos. Brasília: EMBRAPA. 2004. p. 45-60.

CARVALHO, N. O. Hidrossedimentologia Prática. Rio de Janeiro: CPRM-Companhia de Pesquisa em Recursos Minerais. 1994.

COSTA, D. C. et al. Potencial erosivo e índice de anomalias de chuvas no polo de produção de grãos de Paragominas, Pará. In: XVIII Congresso Brasileiro de Agrometeorologia. Belém, p. 1-4, 2013.

CREPANI, E. et al. Zoneamento Ecológico-econômico. In: FLORENZANO, T. G. (Org.) Geomorfologia: Conceitos e tecnologias atuais. São Paulo: Oficina de Textos, 2008. p. $285-318$.

EMBRAPA, Centro Nacional de Pesquisa de Solos. Sistema Brasileiro de Classificação de Solos. 2. Ed. Rio de Janeiro: EMBRAPA. 2006.

FISCH, G. et al. Uma revisão geral do clima da Amazônia. Acta Amazônica. v.28, n. 2, p. 101-126, 1998. https://doi.org/10.1590/1809-43921998282126

GUERRA, A. J. T. O início do processo erosivo. In: GUERRA, A. J. T.; SILVA, A. S.; BOTELHO, R. G. M; (Orgs.) Erosão e Conservação dos Solos: Conceitos, Temas e Aplicações. Rio Janeiro Editora Bertrand Brasil, 2005. 17-55 p.

IBGE - Instituto Brasileiro de Geografia e Estatística. Diretoria de Geociências: coordenação de recursos naturais e estudos ambientais mapeamento de recurso naturais do Brasil. Escala 1:250.000. Documentação técnica geral. Rio de Janeiro, 2018. Disponível em: <http://geoftp.ibge.gov.br/informacoes ambientais/geologia/levantamento geologico/vetores/escala 2 50 mil/DOCUMENTACAO TECNICA MRN.pdf> Acesso em 02/09/2018.

Base pedológica da Amazônia Legal: Base em formato digital referente a levantamento em escala de detalhe compatível com a escala de 1:250.000. Manaus: IBGE/SIPAM, 2001. $<$ https://downloads.ibge.gov.br/downloads geociencias.htm\#> Acesso em 02/09/2018.

INPE - INSTITUTO NACIONAL DE PESQUISAS ESPACIAIS. PRODES - Projeto de Monitoramento por Satélites do Desmatamento na Amazônia Legal. São José dos Campos: Instituto Nacional de Pesquisas $\quad$ Espaciais, 2018. Disponível em: <http://www.dpi.inpe.br/prodesdigital/prodesmunicipal.php> Acesso em 19 de outubro de 2018.

Projeto Topodata: Banco de dados geomorfométricos do Brasil. 2011. Dísponível em: $<$ http://www.webmapit.com.br/inpe/topodata/> acesso em 04 de novembro de 2017.

INMET - INSTITUTO NACIONAL DE METEOROLOGIA. Banco de dados meteorológico para Ensino e Pesquisa. Brasília. 2017.2 Disponível em: <http://www.inmet.gov.br/portal/index.php?r=bdmep/bdmep> Acesso em: 30 de março de 2017.

LIMA, S. R. M. et al. Análise do fator de erosividade da chuva para uma pequena bacia hidrográfica da Amazônia. Revista de Engenharia e Tecnologia. v. 6, n 2, p.184-191, 2014.

LONGLEY, P. A. et al. Sistemas e ciência da Informação geográfica. $3^{\underline{a}}$ ed. Porto Alegre: Bookman, 2013.

LOMBARDI NETO, F.; MOLDENHAUER, W. C. Erosividade da chuva: sua distribuição e relação com perdas de solo em Campinas, SP. Bragantia, Campinas, v.51, n.2, p. 189-196, 1992. https://doi.org/10.1590/S0006-87051992000200009

MAIA, M. A. M.; MARMOS, J. L. (Orgs.) Geodiversidade do estado do Amazonas: Programa geologia do Brasil levantamento da geodiversidade. Manaus: CPRM - Serviço geológico do Brasil 2010.

MARENGO, J. A.; NOBRE, C. Clima da região Amazônica. In: CAVALCANTI, I. F. A. et al. (Orgs.). Tempo e Clima no Brasil. São Paulo: Oficina de Textos, 2009. p. 197-207. 
MOLION, L.C.B. Climatologia Dinâmica da região Amazônica: mecanismos de precipitação. Revista Brasileira de Meteorologia, v. 2, n. 1, p.107-117, 1987.

PEREIRA, J. S.; RODRIGUES, S. C. A erosividade das chuvas na área de influência da UHE Amador Aguiar I, bacia do rio Araguari - MG. Caminhos de Geografia. Uberlândia. v. 19, n. 68 p. 186-199, 2018. https://doi.org/10.14393/RCG196813

QGIS Development Team. QGIS User Guide, Release 2.18: QGIS Project, 2016. Disponível em: https://www.qgis.org/en/site/ acesso em 02/03/2017.

ROSS, J. L. S. Geomorfologia, ambiente e planejamento. 8. ed. São Paulo: Contexto, 2008.

Ecogeografia do Brasil: Subsídios para planejamento ambiental. São Paulo: Oficina de Textos. 2006.

SILVA, A.M. Rainfall erosivity map for Brazil. Catena, Amsterdam, v. 57, n. 3, p. 251-259, 2004. https://doi.org/10.1016/i.catena.2003.11.006

SILVA, A. M. et al. Erosão e Hidrossedimentologia em Bacias Hidrográficas. São Carlos: Editora RiMa. 2009.

SOUZA, V.; GALVANI, E. Determinação do índice de erosividade das chuvas para o município de Umuarama - PR. In: X Simpósio Brasileiros de Climatologia Geográfica. Curitiba. p. 1944 - 1953, 2014.

TRINDADE, A. L. F. et al. Variabilidade espacial da erosividade das chuvas no Brasil. Pesquisa agropecuária brasileira. Brasília, v.51, n.12, p.1918-1928, 2016. https://doi.org/10.1590/s0100$\underline{204 \times 2016001200002}$

WISCHMEIER, W. H.; SMITH, D. D. Predicting rainfall erosion losses, a guide to conservation planning. Agricultural Handbook, Washington, n. 537, 1978, 58p.

Recebido em: 26/02/2019

Aceito para publicação em: 26/08/2020 